\title{
METHODOLOGY OF HEAT TRANSFER AND FLOW RESISTANCE MEASUREMENT FOR MATRICES OF ROTATING REGENERATIVE HEAT EXCHANGERS
}

\author{
Dariusz Butrymowicz ${ }^{1 *}$, Jarosław Karwacki ${ }^{2}$, Roman Kwidziński ${ }^{2}$, Kamil Śmierciew $^{1}$, \\ Jerzy Gagan ${ }^{1}$, Tomasz Przybyliński ${ }^{2}$, Teodor Skiepko ${ }^{1}$, Marek Łapin ${ }^{3}$ \\ ${ }^{1}$ Bialystok University of Technology, Faculty of Mechanical Engineering, ul. Wiejska 45C, 15-351 \\ Bialystok, Poland \\ ${ }^{2}$ Institute Fluid Flow Machinery of PASc, ul. J. Fiszera 14, 80-231 Gdańsk, Poland \\ ${ }^{3}$ RAFAKO S.A., Design Team K132, ul. Łąkowa 33, 47-400 Racibórz, Poland
}

\begin{abstract}
The theoretical basis for the indirect measurement approach of mean heat transfer coefficient for the packed bed based on the modified single blow technique was presented and discussed in the paper. The methodology of this measurement approach dedicated to the matrix of the rotating regenerative gas heater was discussed in detail. The testing stand consisted of a dedicated experimental tunnel with auxiliary equipment and a measurement system are presented. Selected experimental results are presented and discussed for selected types of matrices of regenerative air preheaters for the wide range of Reynolds number of gas. The agreement between the theoretically predicted and measured temperature profiles was demonstrated. The exemplary dimensionless relationships between Colburn heat transfer factor, Darcy flow resistance factor and Reynolds number were presented for the investigated matrices of the regenerative gas heater.
\end{abstract}

Keywords: heat transfer, single blow technique, rotating heat exchanger, regenerator

\section{INTRODUCTION}

The paper deals with an approach of the measurement of heat transfer and flow resistance in matrices of regenerative gas heat exchangers. Heat exchangers may be applied in various processing technologies as well as power engineering. An exemplary application of heat exchangers of this type are regenerative air preheaters commonly applied in power stations. A reference drawing of a regenerative heat exchanger is presented in Fig. 1.

Matrices composed of thermal elements (usually profiled steel sheet) applied in heat exchangers of this type can differ in geometry, materials and, if any, surface coating which results in different conditions of heat transfer and flow resistance. Thus, the decision concerning the selection of a particular type of thermal elements can be made on the basis of knowledge of the heat transfer coefficient and flow resistance coefficient within the velocity range of gas flow in the range of the working conditions of the discussed heat exchanger. Such tests can be carried out for the model matrix composed of the thermal elements that is geometrically adjusted to the measuring tunnel applied in the test. 


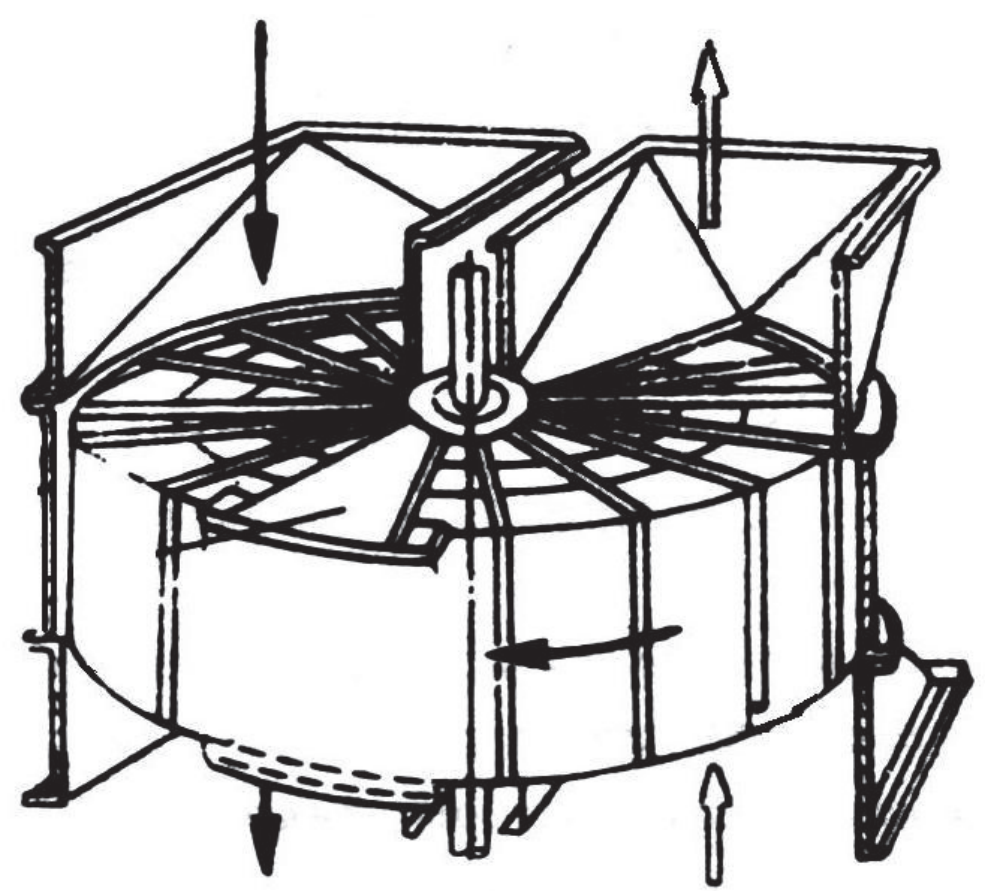

Fig. 1. Rotary air preheater

Usually measurement of the flow resistance is not very difficult. However, the measurement of the heat transfer coefficient may be thought of as a challenge in most cases due to very complicated geometry of the thermal elements. This is the reason why it is impossible to apply the simplest direct methods of the measurement of the heat transfer coefficient that are based on the direct measurement of the temperature of the thermal elements walls, gas temperature distribution as well as heat flux density. This means that in this case an indirect method must be applied. The methodology of such measurement is proposed in this paper.

The indirect approach requires application of the appropriate model of heat transfer in the analysed matrix. Therefore the selection of the appropriate model was discussed in further section of this paper along with appropriate methodology and measurement apparatus dedicated to the matrices of regenerative heat exchangers. Therefore not only the obtained heat transfer data for matrices of a new geometry dedicated to modern regenerative air preheaters may be thought to be a novelty proposed in the paper, but also the detailed measurement procedure and apparatus dedicated appropriately to this type of heat transfer elements as well.

\section{METHODOLOGY OF HEAT TRANSFER COEFFICIENT MEASUREMENT}

The so-called single blow technique is thought to be an efficient method used to experimentally determine the average heat transfer coefficient $\alpha$ in regenerative heat exchangers composed of thermal elements. Heat transfer coefficient is based on the actual surface area of the thermal elements and takes into account convective heat transfer between gas and the thermal element on the wall surface. In the discussed method the average heat transfer coefficient $\alpha$ to be found is determined by means of the comparison of the actual temperature profile of gas (that is heated or cooled in the tested matrix) measured at the outlet of the tested matrix with the predicted one on the basis of the theoretical model. The agreement between the experimental temperature profiles and theoretical prediction depends on the heat transfer coefficient $\alpha$ that is applied in the theoretical model of heat transfer. Various theoretical approaches may be applied in order to predict temperature profile at the outlet for given inlet conditions and the geometry of thermal elements. Below there is a short review of theoretical models which may be applied in the single blow method. 


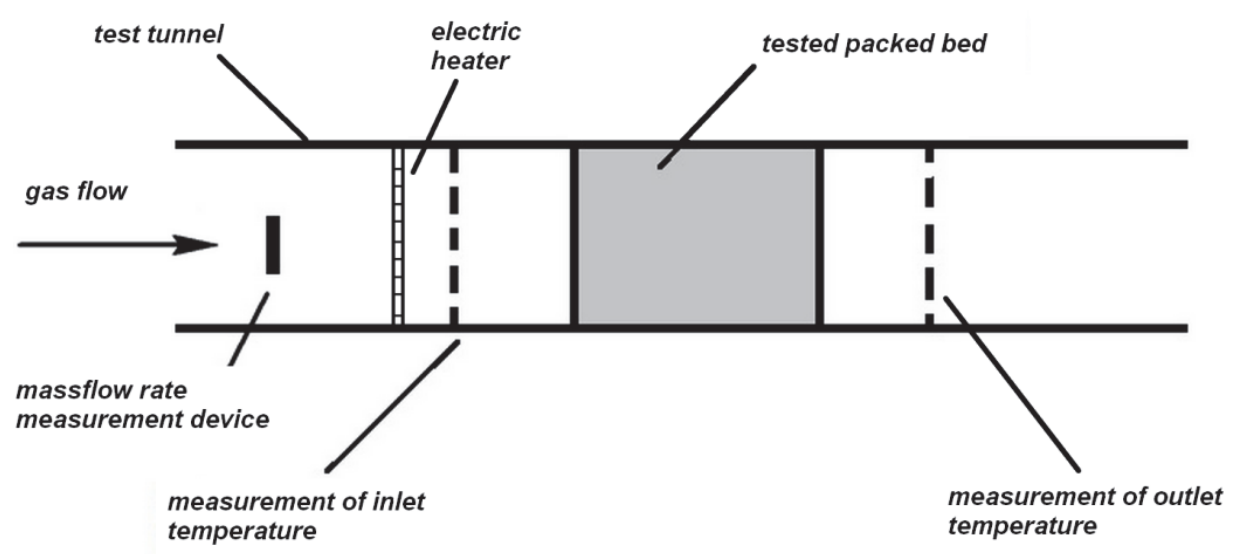

Fig. 2. The idea of the measurement of heat transfer by means of single blow technique

The experimental part of the single blow method is carried out in a wind tunnel (Fig. 2). Because of limitations of the test chamber of the tunnel, usually the entire heat exchanger cannot be tested so the test involves only a matrix composed of thermal elements used in a real heat exchanger. Temperature and pressure measurement points are placed at the inlet and outlet of the tested matrix. Static pressure difference is measured in order to determine the frictional flow resistance. In addition, the velocity of gas flow through the matrix should be also measured. It may be suggested that the temperature of gas flowing through the matrix should be raised above the ambient temperature by approximately 10-20 K. An electrical heating coil made of resistance wires may be applied for this purpose. Due to the required velocity homogeneity, the heating coil should disturb the flow as little as possible. The structure of the coil also affects the gas temperature profile obtained after switching it on or off which is important from the point of view of the theoretical model applied to draw up the measurement results. The simplest models offer analytical solutions for which an immediate temperature leap at the measurement section inlet is assumed. Some theoretical models assume the inlet temperature profile that is described by an exponential function achieved in the experiment. In more complicated numerical models there is no limitation concerning the profile of inlet temperature so the restrictions concerning the heating section (mainly its length in the direction of gas flow) are less important. Due to the homogeneity of velocity profiles required in theoretical models, it is recommended to place a flow straightener (in the form of a honeycomb matrix) before the test section. In order to eliminate the influence of disturbances generated at the tunnel outlet geometry, a similar flow straightener should be also placed at the outlet of the test section. Reduction of the channel hydraulic diameter between the tunnel inlet and the test section is required in order to reduce turbulence level in the flow.

The measurement in the single blow method, which relies on recording the time variability of gas temperature profile directly at the inlet and outlet of the tested matrix which is caused by switching the heating section on or off, is of key importance for the discussed method. The following conditions need to be met before the measurement:

- gas flow is steady state (constant velocity);

- the temperature in the measurement section is constant and equal in the axial and radial directions.

Temperature profiles should be measured for different velocities, involving the whole range of Reynolds numbers expected in the range of the operating conditions of the heat exchanger.

Temperature profiles recorded during the single blow technique measurements are used when solving equations modelling heat exchange in the tested matrix. The measured temperature leap or profile at the inlet to the test section is the boundary condition for the model equations. The measured temperature profile at the outlet of the test section should be predicted on the basis of the model. However, 
theoretical and measured outlet temperature profiles may be compared in several ways. Three methods are proposed in literature:

- direct comparison of the whole temperature distributions; the method of the least squares interpolation can be applied for data fitting in this case;

- fitting distributions in several (e.g. five) selected points; usually this fitting method requires using slightly different heat transfer coefficient values for each point in the calculations; therefore the average value of heat transfer coefficient may be thought to be the final result;

- the maximum slope method; the relationship for the maximum slope of the outlet temperature distribution may be derived on the basis of the heat transfer model equations; on the basis of the maximum slope of the experimental curve the heat transfer coefficient is determined; this method enables to directly calculate heat transfer coefficient from the above relationship.

Although the above-mentioned methods may be thought as equivalent, in practical application they differ in the achievable accuracy of determination of the heat transfer coefficient.

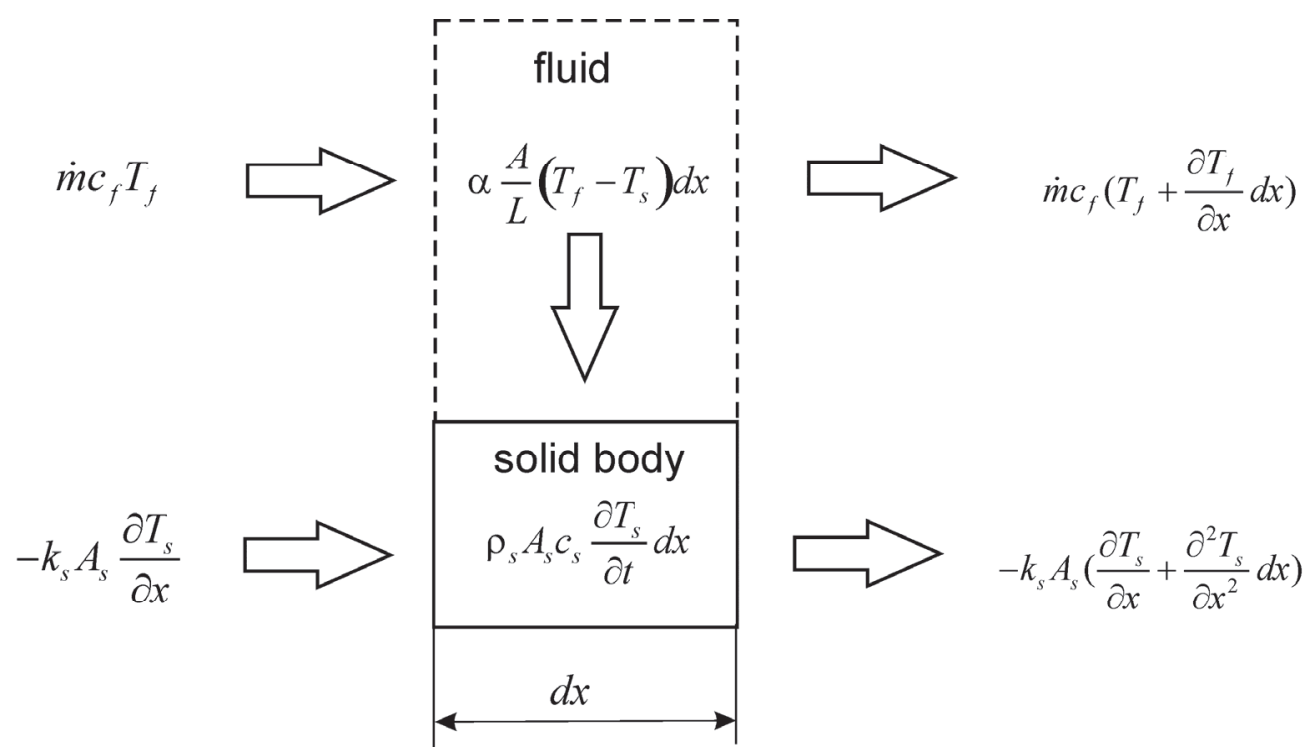

Fig. 3. Energy balance for fluid $(f)$ and solid body $(s)$ for heater exchanger element

The most basic one-dimensional model of transient heat transfer between a porous body and a fluid flowing through it was proposed by Anzelius (1926). The model became the basis for many further modifications and is still being developed by removing the numerous simplifications assumed by the author in order to obtain an analytical solution of the model equations. Anzelius (1926) model is based on the energy balance for a solid body element (porous or perforated packing of the exchanger) in the situation presented in Fig. 3.

The following assumptions were made:

- the physical properties of fluid are independent of temperature;

- gas flow is steady state $(\dot{m}=$ const $)$;

- the solid has a homogeneous structure;

- the thermal conductivity perpendicular to the flow direction is infinite (both for the fluid and for the solid body);

- the thermal conductivity of the fluid in the flow direction equals to zero;

- the external casing of the heat exchanger is adiabatic;

- initially the temperature in the exchanger is uniform $\left(T_{s}=T_{f}=T_{i}\right)$;

- initially the fluid temperature leaps from $T_{i}$ to $T_{f 1}$ and then it remains steady.

Balance equations of the element of fluid and solid body in the non-dimensional form are as follows: 


$$
\begin{gathered}
\frac{\partial T_{f}}{\partial z}=T_{s}-T_{f} \\
\frac{\partial T_{s}}{\partial \tau}=\lambda N T U \frac{\partial^{2} T_{s}}{\partial z^{2}}+\left(T_{f}-T_{s}\right)
\end{gathered}
$$

where non-dimensional time is defined as follows:

$$
\tau=t \frac{\alpha A}{m_{s} c_{s}}
$$

and non-dimensional coordinate is defined as:

$$
z=N T U \frac{x}{L}
$$

After the transformation of the above equations, two new coefficients appear in the energy balance for the solid body, namely the number of heat transfer units:

$$
N T U=\frac{\alpha A}{\dot{m} c_{f}}
$$

and a parameter connected with solid body thermal conductivity $k_{s}$ in the direction $\theta$ parallel to the flow direction:

$$
\lambda=\frac{k_{s} A_{s}}{\dot{m} c_{f} L}
$$

If conductivity can be ignored, eqs. (1) and (2) have analytical solutions developed by Schumann (1929) in the form:

$$
\begin{aligned}
& \theta_{s}=1-e^{-(z+\tau)} \sum_{n=0}^{\infty} z^{n} \frac{d^{n}}{d(z \tau)^{n}}\left(J_{0}(2 i \sqrt{z \tau})\right) \\
& \theta_{f}=1-e^{-(z+\tau)} \sum_{n=1}^{\infty} z^{n} \frac{d^{n}}{d(z \tau)^{n}}\left(J_{0}(2 i \sqrt{z \tau})\right)
\end{aligned}
$$

where $\theta$ is non-dimensional temperature defined as follows:

$$
\theta=\frac{T-T_{i}}{T_{f 1}-T_{i}}
$$

The distributions of temperatures obtained from the above Schumann analytical solution can be used to determine the heat transfer coefficient $\alpha$ if the experiment well agrees with the boundary and initial conditions assumed in the model. Then, comparing the measured temperature distribution $T_{f}(t)$ at the heat exchanger (matrix) outlet with the theoretical temperature distribution the spot $z=N T U$, the best fit will be achieved if the value $\alpha$ specific for the tested exchanger is used (Furnas, 1932).

Instead of comparing temperature profiles, their derivatives can be used, and in particular their maximum values. Locke (1950) differentiated the solution for the outlet temperature $T_{f 2}=T_{f}(\tau, z=N T U)$ at constant $N T U$ and obtained the relationship for the slope $S$ of the curve describing evolution of temperature $T_{f 2}$ in dimensionless coordinates. This makes it possible to determine the derivative from the experimental profile of outlet temperature $T_{f 2}(t)$ and the experimental value $S_{\max }$. For that value it is possible to obtain the corresponding $N T U$ value, and then find the needed value of coefficient $\alpha$. 
Solving the model equations taking into consideration heat conductivity along the solid body is only possible with numerical methods. The necessary calculations were done e.g. by Howard (1964), and his findings in the form of tables and graphs of function $N T U=f\left(S_{\max }\right)$ for selected values $\lambda$ within the range of $[0.005 \ldots 10, \infty]$ are also included in the paper presented by Pucci et al. (1967). The effect of the parameter $\lambda$ on the determination of $N T U$ is significant, especially when $N T U>10$. Due to the considerable slope of the curve $N T U=f\left(S_{\max }\right)$ this approach of determination of $\alpha$ with the maximum slope $S_{\max }$ involves considerable error for certain combinations of parameters $S_{\max }$ and $\lambda$. Various initial temperature profiles of the fluid entering the analysed various cases of regenerative heater matrix comprised of identical parallel thin walled ducts and temperature of the matrix casing were analysed also by Larsen (1967).

The accuracy of determining heat transfer coefficient using the single blow method can be improved by extending the Anzelius model, providing that:

- the leap of the inlet temperature of the fluid occurs not immediately;

- heat conductivity in the solid body occurs not only in the axial direction but also in the radial direction;

- the external wall of the heat exchanger (matrix) is not adiabatic; consequently there is a radial temperature gradient in the heat exchanger;

- pressure drop of the fluid flowing through the heat exchanger (matrix) changes of its temperature due to Joule-Thomson effect;

- the distribution of fluid velocity in the axial direction is heterogeneous due to disturbances of gas flow occurring at the elements of the heat exchanger (matrix).

Table 1. Features of heat transfer models that may be applied in single blow method

\begin{tabular}{|l|c|c|c|c|c|c|c|}
\hline \multicolumn{1}{|c|}{ Model } & $\begin{array}{c}\text { Axial } \\
\text { thermal } \\
\text { conduction }\end{array}$ & $\begin{array}{c}\text { Radial } \\
\text { thermal } \\
\text { conduction }\end{array}$ & $\begin{array}{c}\text { Adiabatic } \\
\text { matrix } \\
\text { casing }\end{array}$ & $\begin{array}{c}\text { Joule- } \\
\text { Thomson } \\
\text { effect }\end{array}$ & $\begin{array}{c}\text { Axial } \\
\text { dispersion }\end{array}$ & $\begin{array}{c}\text { Inlet } \\
\text { temperature } \\
\text { profile }\end{array}$ & $\begin{array}{c}\text { Analytical } \\
\text { solution }\end{array}$ \\
\hline Anzelius (1926) & + & - & + & - & - & leap & - \\
\hline Schumann (1929) & - & - & + & - & - & leap & + \\
\hline Larsen (1967) & - & - & - & - & - & leap & + \\
\hline $\begin{array}{l}\text { Liang and Yang } \\
(1975)\end{array}$ & - & - & + & - & - & exponential & + \\
\hline fai et al. (1984) & + & - & + & - & - & unrestricted & - \\
\hline $\begin{array}{l}\text { Chen and Chang } \\
(1996)\end{array}$ & + & - & - & - & - & unrestricted & - \\
\hline $\begin{array}{l}\text { Chen and Chang } \\
(1997)\end{array}$ & + & - & - & + & - & unrestricted & - \\
\hline Chen et al. (1999) & + & + & - & + & - & unrestricted & - \\
\hline Luo et al. (2001) & + & - & + & + & - & - \\
\hline
\end{tabular}

The modification of the initial conditions of Schumann solution proposed by Liang and Yang (1975) minimizes problems connected with experimental realisation of the non-immediate temperature leap at the tested exchanger inlet. Liang and Yang model was further extended by Cai et al. (1984) by taking into consideration also the conductivity of the solid body in the axial direction. The solution of this model could be obtained by a numerical procedure, however. In this case the temperature profile at the exchanger inlet can be any function of time. Chen and Chang (1996) added to the model an equation describing the heat transfer between fluid and the casing. They took into account the Joule-Thomson effect (Chen and Chang, 1997), and finally also radial conductivity (Chang et al., 1999). Luo et al. 
(2001), highlighted the impact of disturbances of fluid flow caused by the elements of exchanger packing (so-called axial dispersion). General characteristics of the above mentioned models are presented in Table 1. However, taking into consideration that usually measurements cover a large number of test runs, the most useful will be the analytical solution of the temperature profile at the outlet of the tested matrix.

One of the sources of inaccuracy of the heat transfer coefficient $\alpha$ determined by means of the single blow method is the difficulty of the realisation of the immediate temperature leap at the exchanger inlet. Due to the thermal capacity of the heater all temperature changes always occur at a certain time span. Liang and Yang (1975) proposed dimensionless inlet temperature profiles obtained in the discussed test method after switching the heater on or off as the exponential function:

$$
\theta_{f}(\tau, 0)=1-e^{-\tau / \tau^{*}}
$$

where $\tau^{*}$ is an experimentally determined dimensionless constant. The above temperature profile can be used as the boundary condition for modified Anzelius model equations (Liang and Yang, 1975). In the equation for fluid energy balance its thermal capacity was taken into consideration so the equation for gas energy balance was obtained as follows:

$$
\frac{\partial \theta_{f}}{\partial \tau}+b_{1} \frac{\partial \theta_{f}}{\partial z}=b_{2}\left(\theta_{s}-\theta_{f}\right)
$$

and in the solid body the thermal conductivity was ignored so that Eq. (2) was used. In a dimensionless form this equation can be presented as follows:

$$
\frac{\partial \theta_{s}}{\partial \tau}=\theta_{f}-\theta_{s}
$$

The coefficients $b_{1}$ and $b_{2}$ in Eq. (11) are constant and defined as follows:

$$
b_{1}=b_{2} \frac{v_{f}}{A_{f, \min }}, \quad b_{2}=\frac{m_{s} c_{s}}{m_{f} c_{f}}
$$

It must be remembered that temperature $T_{f 1}$, necessary to calculate $\theta$ should be a value settled at the inlet after a sufficiently long time after switching the heater on or off. Equations (11) and (12) with boundary condition Eq. (10) and the following initial conditions:

$$
\theta_{s}(0, z)=\theta_{f}(0, z)=0
$$

were solved (Liang and Yang, 1975) with the use of the Laplace transform which gave a set of equations:

$$
\begin{gathered}
p \bar{\theta}_{f}+b_{1} \frac{d \bar{\theta}_{f}}{d z}=b_{2}\left(\bar{\theta}_{s}-\bar{\theta}_{f}\right) \\
p \bar{\theta}_{s}+=\bar{\theta}_{f}-\bar{\theta}_{s} \\
\bar{\theta}_{f}(p, 0)=\frac{1}{\tau^{*} p\left(p+\frac{1}{\tau^{*}}\right)}
\end{gathered}
$$

Where $\bar{\theta}$ denotes the transform, and $p$ is its argument. The solution to the set of Eqs. $(15)-(17)$ in relation to $\bar{\theta}_{f}$ is as follows (Liang and Yang, 1975): 


$$
\bar{\theta}_{f}=\frac{\exp \left(-\frac{p}{b_{1}}\left(1+\frac{b_{2}}{1+p}\right) z\right)}{\tau^{*} p\left(p+\frac{1}{\tau^{*}}\right)}
$$

Finding the inverse Laplace transform for Eq. (18) at $z=N T U$, the following relationships describing the profile of dimensionless temperature at the heat exchanger outlet are obtained:

- if $\tau<t^{*}$ (i.e.: $t<L / w_{f}$ ):

$$
\theta_{f}(\tau, N T U)=0
$$

- when $\tau \geq t^{*}$ (i.e.: $\left.t \geq L / w_{f}\right)$ :

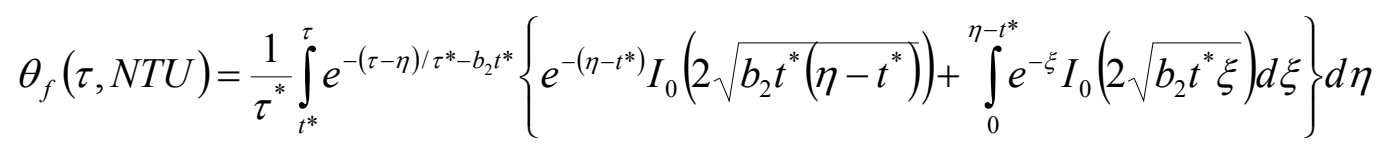

In the above relationships the symbol $t^{*}$ denotes dimensionless time defined as follows:

$$
t^{*}=\frac{N T U}{b_{1}}
$$

and $w_{f}$ is the mean velocity of fluid in the heat exchanger.

Provided the relatively high numerical cost connected with the application of more complex mathematical models of heat transfer in regenerators, the authors decided to use the above modified Liang and Yang model (Liang and Yang, 1975). The key element in this model is the consideration of the exponential character of the inlet temperature profile which allows to avoid a considerable error resulting from the impossibility to execute an immediate leap of temperature at the inlet of the tested matrix. It is recognised that the accuracy of this model should be satisfactory for indirect measurement of the heat transfer coefficient.

The heat transfer coefficient determined on the basis of the above methodology can be presented in a dimensionless form as a function of Colburn coefficient $j$ versus Reynolds number Re. Similarly, the measurement of pressure differences between the inlet and the outlet of the tested matrix, including gas velocity measurement, can be used to determine the frictional resistance as a function of Fanning coefficient $f$ versus Reynolds number Re. The following correlations for $j$ and $f$ coefficients as the functions of Reynolds number $R e$ are proposed:

$$
\begin{aligned}
& j=c_{j} \operatorname{Re}^{m_{j}} \\
& f=c_{f} \operatorname{Re}^{m_{f}}
\end{aligned}
$$

It may be expected that relationships between the above coefficient and Reynolds number are not a monotonic function in all cases of the thermal plate geometries. Due to a variety of the possible thermal plate geometry the opened or closed gas flow ducts through the matrix are possible. In the second case gas flow through the matrix occurs similarly as in the case of the closed channel. In this case it may be supposed that the above discussed coefficients drop to minimum level for the range of Reynolds numbers corresponding to the transient region of gas flow through the tested matrix, i.e. between the laminar and the turbulent flow regime. Therefore a better fitting of experimental data to the above relationships is achieved if the constants $c$ and $m$ are determined separately for each of the flow types, i.e. laminar, transient, and turbulent.

The Fanning resistance coefficient $f$ is calculated from the following relation: 


$$
f=\frac{1}{4} \frac{D_{h}}{L}\left(2 \rho \frac{\Delta p}{\dot{G}^{2}}-K_{c}-K_{e}\right)
$$

The coefficients $K_{c}$ and $K_{\mathrm{e}}$ were predicted on the basis of the recommendations of Kays and London (1976). The relationship for Darcy friction factor is as follows:

$$
f_{D}=4 f
$$

Hence, the Reynolds number is also known:

$$
\operatorname{Re}=\frac{w D_{h}}{v}
$$

From the definition of Colburn coefficient:

$$
j=\frac{N u}{\operatorname{RePr}^{1 / 3}}
$$

and the Nusselt number:

$$
N u=\frac{\alpha D_{h}}{k}
$$

a final formula for the calculation of heat transfer coefficient is obtained:

$$
\alpha=C \frac{k}{D_{h}} \operatorname{Re}^{m+1} \operatorname{Pr}^{1 / 3}
$$

\section{MEASUREMENT APPARATUS}

The measurement tunnel along with auxiliary measurement equipment is presented in Fig. 4. This channel equipped with the electric heater dedicated to the measurement of heat transfer and pressure drop characteristics for the matrices consisted of thermal plates used in regenerative air preheaters used in power engineering. The internal dimensions of the tunnel section were: $320 \mathrm{~mm} \times 320 \mathrm{~mm}$.

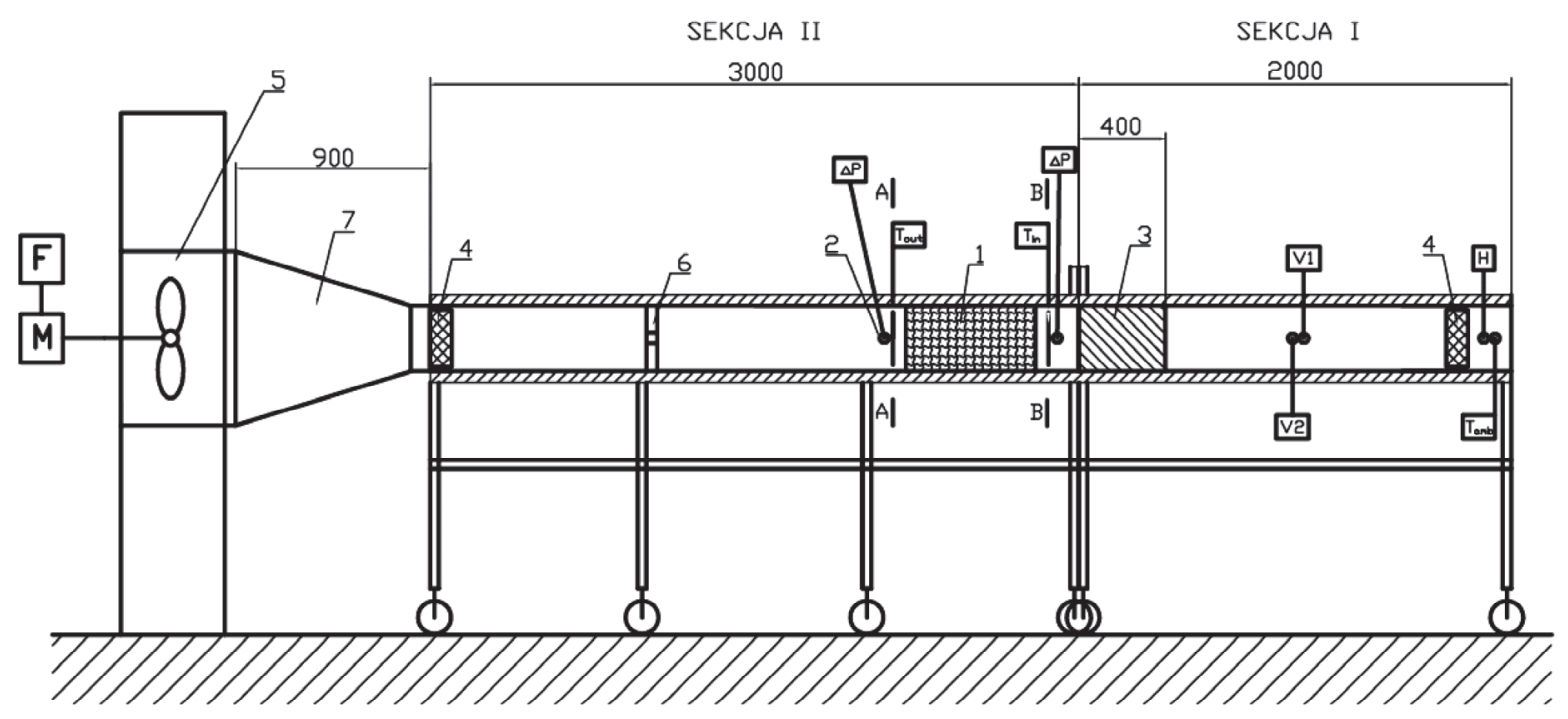

Fig. 4. Schematic diagram of testing stand:

1 - packages of investigating elements, 2 - pressure measuring point, 3 - electrical heater for heating air, 4 - flow rectifier , 5 - fan, 6 - pile up elements DEBIMO, 7 - diffuser 
It is possible to control air mass flux in the tunnel by changing the centrifugal exhaust fan rotational speed. It is also possible to control the electric heater capacity. The test stand consists of three parts:

- the inlet section with an electrical heater;

- the measurement section with the tested package of heating elements;

- $\quad$ an exhaust fan with a diffuser.

The sections were connected in a way which allows easy disassembly. The connections ensure tightness and fan vibration damping. The channel was made of laminar boards composed of a light polyurethane foam core covered bilaterally with a layer of hard PVC. This structure satisfies the assumption of adiabatic screen while at the same time providing sufficient structural strength. The use of strengthened bearing structure of the tunnel was necessary because the mass of the tested packing can exceed $100 \mathrm{~kg}$. Also, it is necessary to squeeze the tested matrix with considerable strength so as to obtain the real geometry of the flow channels in heat exchanger.

The structure of the flow channel of the first two tunnel sections was divided into two independent elements, namely a glued flume and a removable cover. This structure allows for easy inspection of the interior of the channel. A foamed rubber gasket was glued on the surface of the cover and flume contact. When the stand is working, vacuum of a few up to a few hundred Pa occurs in each part of the flow channel. This results in pressing the cover to the flume and thus sealing the channel.

Two air velocity transducers were placed at the middle part of the inlet section: the first was a fan type, and the second one was a thermo-anemometric type. The thermo-anemometric air velocity transducer cannot be placed just after the air heater because a leap temperature change causes considerable deviations of temperature readings. At the inlet of the air heater in a plane perpendicular to the flow direction culverts were made for a movable thermo-anemometric probe. The culverts were used in measuring velocity profiles in the tunnel.

a)

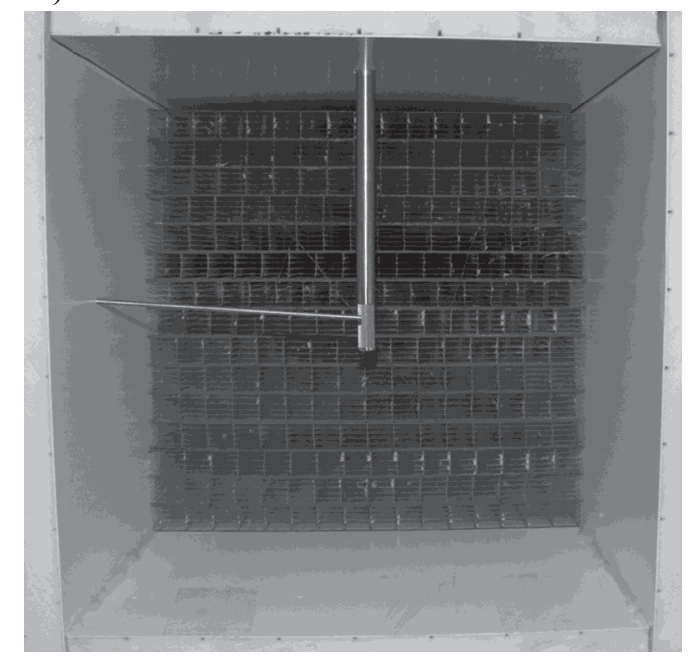

b)

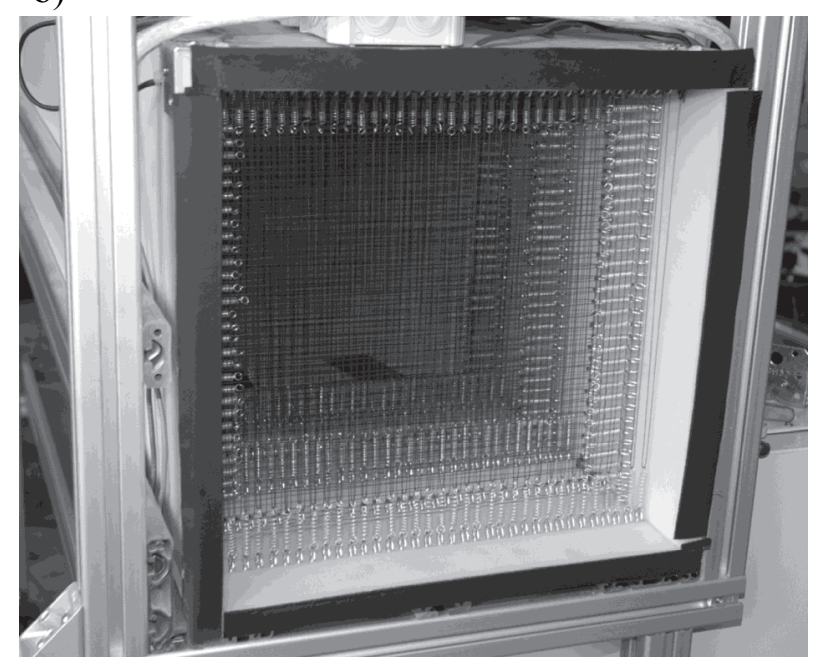

Fig. 5. View of the elements of the test tunnel: a) flow straightener; b) electrical heater

A flow straightener was placed at the inlet of the tunnel, see Fig. 5a. The selected material had low thermal energy capacity and thin walls. The straightener had flow channels with dimensions: $2 \mathrm{~mm} \times$ $19 \mathrm{~mm}$ and length $100 \mathrm{~mm}$. This solution of the inlet part of the tunnel equipped with the straightener enabled to obtain regular velocity profiles in the further part of the tunnel. A sensor of humidity and a sensor of the inlet temperature were installed directly before the straightener. 


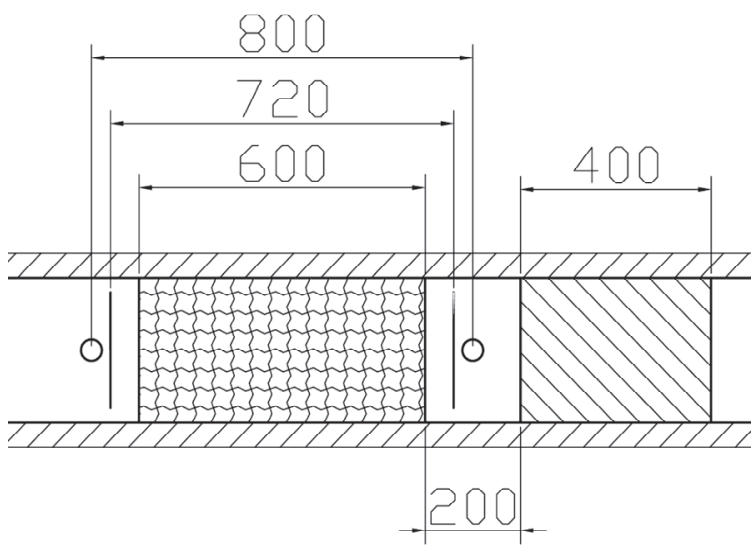

Fig. 6. Schematic of the test section and electrical heater section configuration

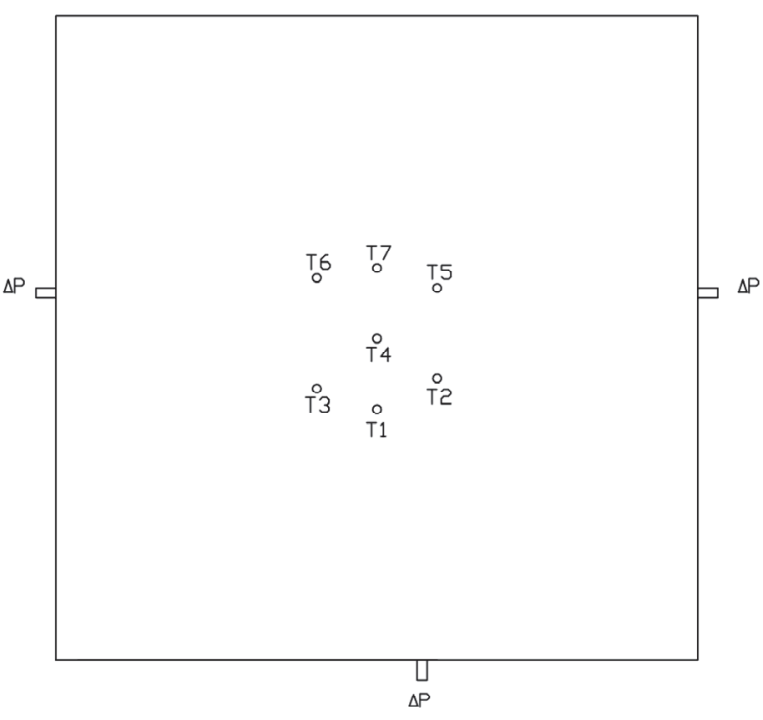

Fig. 7. The configuration of thermocouples and locations of pressure gauges at the cross-section A-A, see Fig. 3

In the further part of the tunnel inlet section the electric heater of the total thermal capacity $20 \mathrm{~kW}$ was inserted, see Fig. 5b. The heater consisted of 10 heating coils of the thermal capacity $2 \mathrm{~kW}$ each one. The heating coils could be switched on or off individually which enabled precise control of the required heater capacity. The heater was made so as to ensure the lowest thermal inertia as possible. For that purpose $0.32 \mathrm{~mm}$ wire was used to manufacture the applied heating coils.

The view of the test section part is presented in Fig. 6. The schematic of configuration of temperature and pressure measurement points is shown in Fig. 7. In the front part of the section there was a matrix composed of the tested thermal elements. The temperature measurement cross-section was located 60 $\mathrm{mm}$ before and after the tested matrix. Stub pipes were applied to measure the pressure drop at the matrix. The location of the temperature measurement cross-section presented in Fig. 7 was chosen to meet the requirements of the selected model that predicts the temperature profile, see Section 2. The selected model of Liang and Yang (Liang and Yang, 1975) is valid for uniform velocity distribution along the analysed channel. Therefore the regions of boundary layers should be eliminated from the analysis. The locations of the thermocouples presented in Fig. 7 were selected to be in the region of the most uniform velocity distribution in the test wind channel. Therefore the different distribution of the temperature sensors would not yield any additional results which was proved by the authors during preliminary tests.

Measurements at the test stand were recorded with the use of a module measurement system NI SCXI and an 18-bit measuring board NI 6251. The system can record at the maximum frequency of $330 \mathrm{kHz}$. In measurements with multiple channels, the maximum acquisition frequency for a single channel was 330000 per the number of channels. Data recording of the maximum possible frequency is connected with lowering the accuracy of the measurements, however. Therefore data were recorded at $10 \mathrm{~Hz}$ in the discussed experiments.

The following basic parameters are measured on the test stand:

- air temperature at the tunnel inlet;

- air temperature at the tested matrix inlet ;

- air temperature at the tested matrix outlet;

- static pressure drop at the tested matrix;

- air flow rate;

- air humidity the channel inlet of the heating section. 
Additionally, in order to verify the tunnel operation and to increase the accuracy of the measurements, the measurements of the following quantities were carried out:

- velocity profile in the cross-section at the air heater inlet for selected air flow rates;

- temperature profile at the inlet to the tested matrix;

- dynamics of temperature sensors used in the measurements.

The temperature at the tunnel inlet was measured with use of a typical thermoelectric temperature sensor CZAKI Tp 361. The temperatures at the inlet and the outlet of the tested matrix were measured with unsheathed thermocouples OMEGA CHAL-005. These sensors have very low thermal inertia. In practice, at the frequency of $10 \mathrm{~Hz}$ the inaccuracy of the temperature measurement resulting from the dynamic reaction of the sensor is negligible and does not require any corrections. This was confirmed by tests using OMEGA CHAL-002 sensor of $0.05 \mathrm{~mm}$ thermocouple wire diameter. The calibration procedure involved the achievement of steady state at the testing stand and comparison of all the readings of particular temperature sensors with the temperature sensor at the channel inlet. The maximum spread of the temperature readings measured in one cross-section in relation to the mean temperatures was $\pm 0.15 \mathrm{~K}$.

The air flow rate in the tunnel can only be determined on the basis of the mean flow velocity. Flow velocity was measured using three measuring instruments. The measurement with KIMO DEBIMO measuring blades with KIMO CP3003 differential pressure transducer was recognized as the baseline measurement. This measurement was recorded in a measurement system. The maximum inaccuracy of the measurement for this measurement path was $\pm 6 \%$ of the readings. DEBIMO measurement facility was calibrated and verified by means of comparing it with the averaged measurement based on velocity profiles for selected flow rate ranges. The test measurements of velocity profiles were carried out with the use of TSI 8455-25 probe. Additionally, during the measurement readings of TESTO 435-4 measuring instrument of $60 \mathrm{~mm}$ vane probe diameter and Delta OHM DH 2103.1 meter with a thermoanemometric probe were recorded.

The pressure drop at the tested matrix was measured with a differential pressure sensor Deltabar $\mathrm{S}$ PMD70 of ENDRESS and HAUSER. The maximum measurement range of the sensor is $1000 \mathrm{~Pa}$. However, in order to improve the resolution and thus the accuracy of measurements the range was adjusted to $500 \mathrm{~Pa}$. The sensor measurement accuracy was $\pm 0.075 \%$ of the full capacity. It means that the maximum systematic error of the measurement of the sensor used in the test was $0.75 \mathrm{~Pa}$. Electrical signals 4-20 mA generated by the differential pressure transducers were measured with a NI SCXI 1125 amplifier with an adjusted measurement range.

\section{THERMAL ELEMENTS}

This paper describes the results obtained for two kinds of thermal elements geometry. The drawing of the thermal element of the first tested type after adjusting its dimensions to the test wind tunnel is presented in Fig. 8. A profile of the second type of the tested element is presented in Fig. 9.

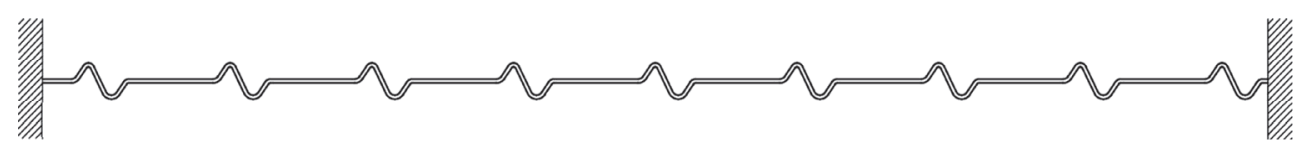

Fig. 8. Thermal element No. 1 geometry

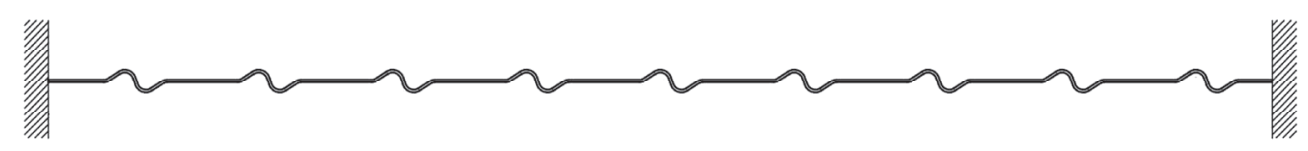

Fig. 9. Thermal element No. 2 geometry 
Figure 10a presents the view of the matrix composed of the thermal elements of this type along with flat plates inserted inside the test tunnel. This type of the thermal elements is referred to as Thermal Elements No. 1 (TE 1) in this study. The other type of the tested thermal element is presented in Fig. 8. In this study this packing is referred to as Thermal Element No. 2 (TE 2). Figure 10b presents the view of the matrix composed of the heating elements of this type inserted inside the test tunnel. The dimensions of the matrix composed of the tested packing elements were $320 \mathrm{~mm} \times 600 \mathrm{~mm}$.

a)

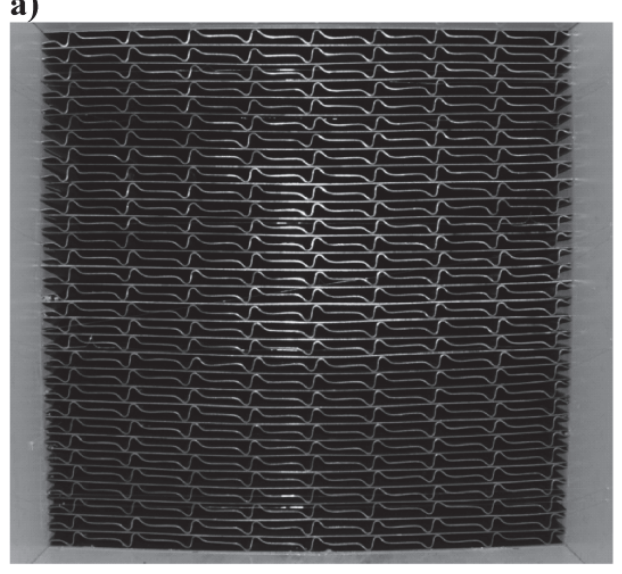

b)

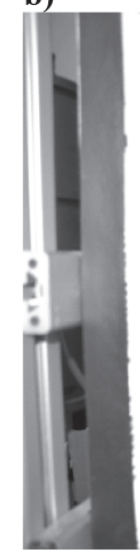

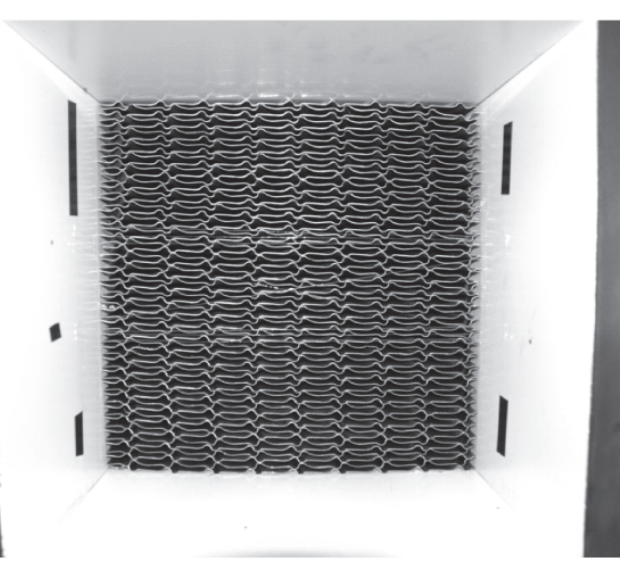

Fig. 10. Photo of matrices composed of the thermal elements inserted in the test wind tunnel: a) thermal elements No. $1 ; b)$ thermal elements No. 2

It should be noted that the geometry of the heating elements may be deformed to a certain extent after the preparation of the matrix because thermal elements may be squeezed to ensure nominal matrix dimensions referring to the actual regenerative heat exchanger geometry. It is impossible, however, to precisely identify the actual geometry of the thermal elements inserted in the test tunnel or inside the heat exchanger.

The experiments covered also the identification of the geometry of the thermal elements along with their mass. In order to identify the geometry of the heating elements, measurements were carried out using NIKON TS-100F optical microscope and ZEISS EVO 40 scanning electron microscope. Mass of the elements was measured with a laboratory balance RADWAG PS 8000/C/1 of $8000 \mathrm{~g}$ maximum capacity and guaranteed measurement accuracy of $\pm 0.01 \mathrm{~g}$. Mass measurement results of the tested heating elements are presented in Table 2.

Table 2. Mass of the tested thermal elements

\begin{tabular}{|l|c|}
\hline \multicolumn{1}{|c|}{ Type of the thermal element } & Mass of single element \\
\hline TE1 & $1106.18 \mathrm{~g}$ \\
\hline $\begin{array}{l}\text { Flat plate dedicated to matrix } \\
\text { composed of TE1 }\end{array}$ & $1483.77 \mathrm{~g}$ \\
\hline TE2 & $1775.41 \mathrm{~g}$ \\
\hline
\end{tabular}

The actual width of the elements used in the tests was measured with identification of the actual profile shape of the cross-section of the element. The measurement was repeated (at least five times in each case) for each profile of the thermal element. A non-stretchy tape sticking to the plate surface was used in the measurement and its length was measured. The hydraulic diameters of channels for the tested thermal elements obtained on the basis of identification of the tested elements geometry were: for TE1 $D_{h}=9.10 \mathrm{~mm}$, and for TE2 $D_{h}=6.98 \mathrm{~mm}$. 
Tests of the thermal elements covered by the protective coatings were also carried out with the same methodology. However, the details concerning these measurements and thermal behaviour of inhomogeneous thermal plates go beyond the scope of this paper. In these cases due to the necessity to take protective coating into consideration the identification of geometry is more complicated and requires the use of 3D laser scanner, however.

It must be emphasized that regarding the need to determine the heat transfer coefficient the most important parameters are the identification of the geometry of the thermal element and specifically the hydraulic diameter of the flow channels as well as the mass of a single element. These quantities were measured and then their actual values were used in the measurement procedure.

\section{RESULTS OF MEASURMENTS}

Heat transfer coefficients for the two types of matrices were determined with the methodology described in Section 2. An exemplary comparison of the measured and calculated temperature profiles at the tested matrix inlet is presented in Fig. 11.

a)

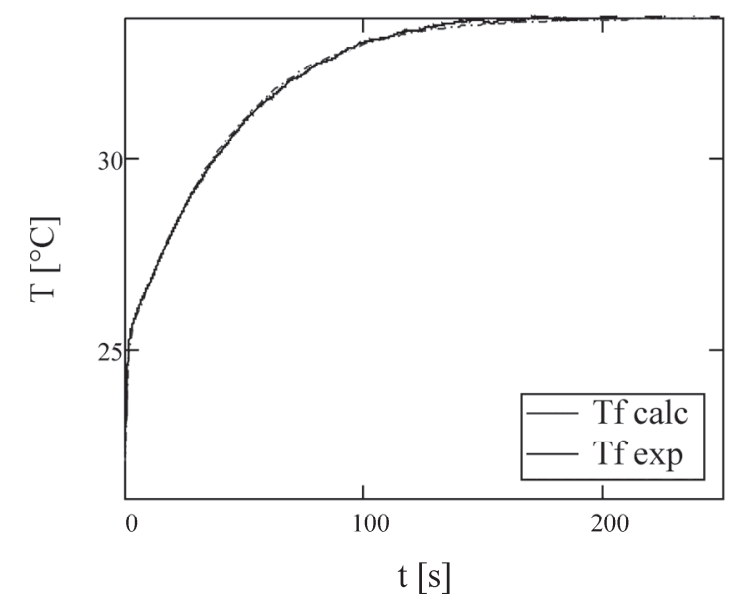

b)

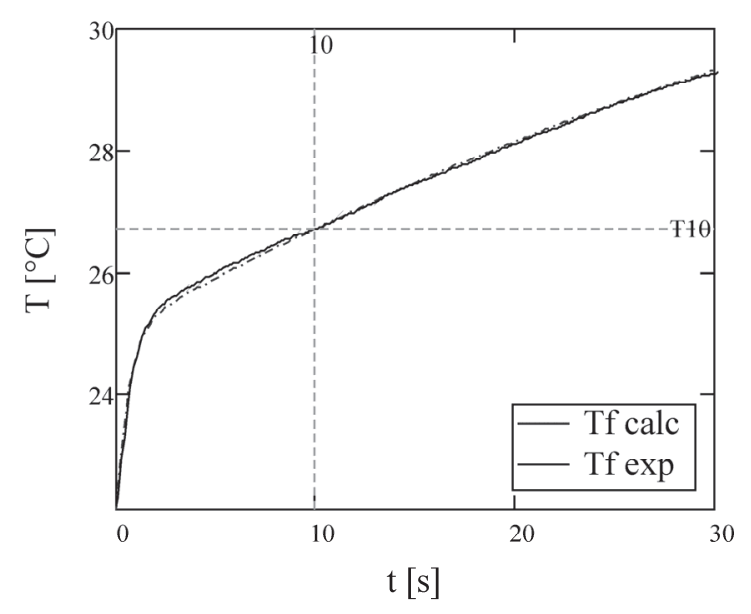

Fig. 11. Comparison of the measured and calculated average air temperature profile at the inlet to the tested matrix composed of TE1 for $R \mathrm{e}=7357$ : a) full measurement period; b) first 30 seconds of the measurement

The measured dimensionless heat transfer and pressure drop coefficients described by Eq. (22) and Eq. (23), respectively, are presented graphically in Figs. 12-15.

Because of the course of variability of Colburn coefficient and Darcy factor for TE1, the discussed correlations given by Eq. (22) and Eq. (23) were drawn up for three ranges of Reynolds number values: $600 \leq R e \leq 2500 ; 2500<R e \leq 5300$, and $5300<R e<8000$. For a matrix composed of TE2 a monotonic variability of these coefficients was obtained, hence one correlation was drawn up for the range of Reynolds numbers of $800 \leq R e \leq 7100$. The values of constants $C_{j}, C_{f}, m_{j}$, and $m_{f}$ are presented elsewhere (Butrymowicz et al., 2013).

It should be noted that a relatively worse fit of the obtained correlations for the range of the largest Reynolds numbers results from the fact that the Colburn coefficient $j$ and Fanning resistance coefficient $f$ (and thus the Darcy factor $f_{D}$ ) in this range are almost constant. It should be also noticed that the obtained relationships of $j(R e)$ and $f_{D}(R e)$ were similar for both of the tested thermal elements TE1 and TE2, which taking into account literature data may be thought of as a result indicating the reliability and accuracy of the obtained results. 


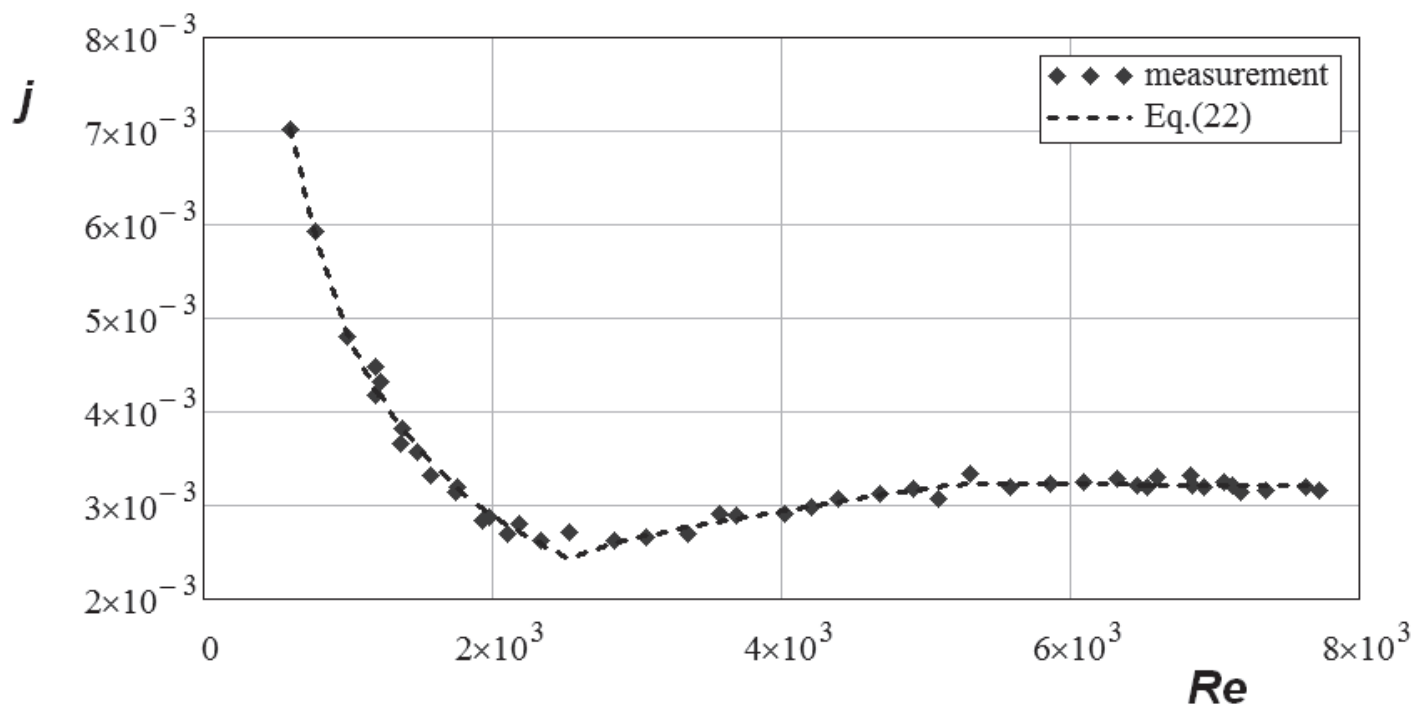

Fig. 12. The relationship between Colburn coefficient $j$ and Reynolds number for matrix composed of TE1

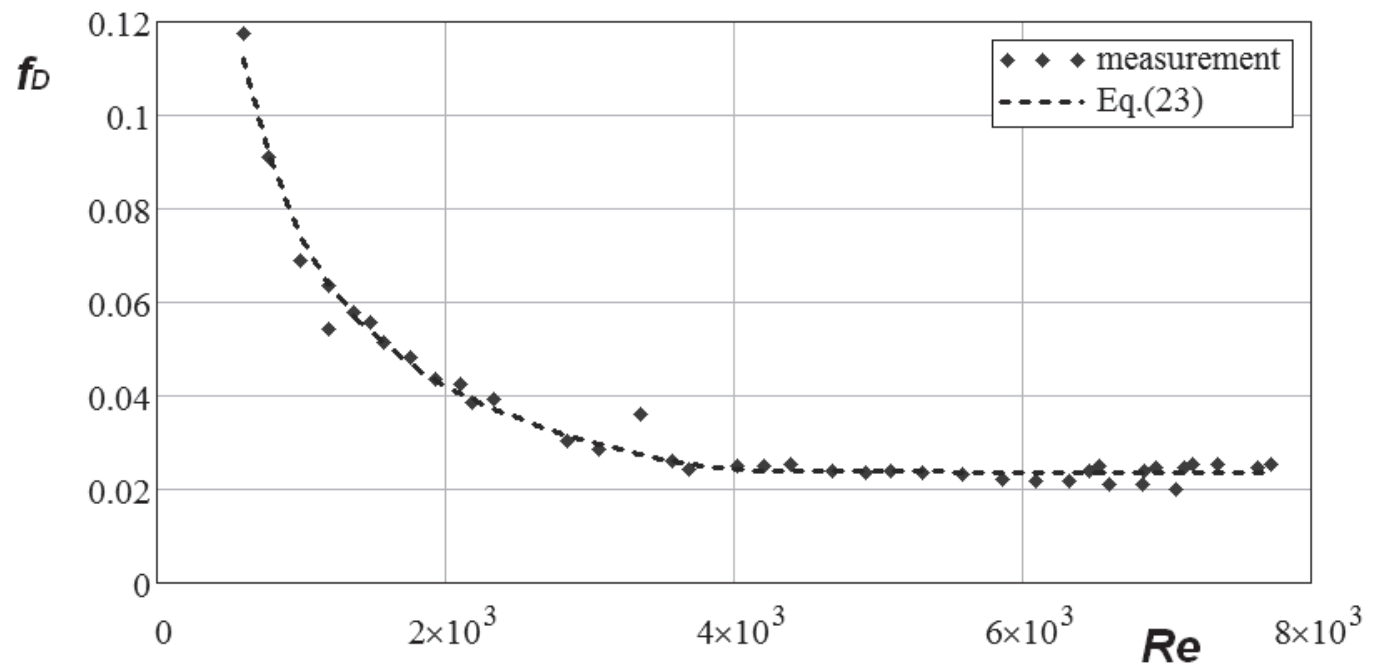

Fig. 13. The relationship between Darcy coefficient $f_{D}$ and Reynolds number for matrix composed of TE1

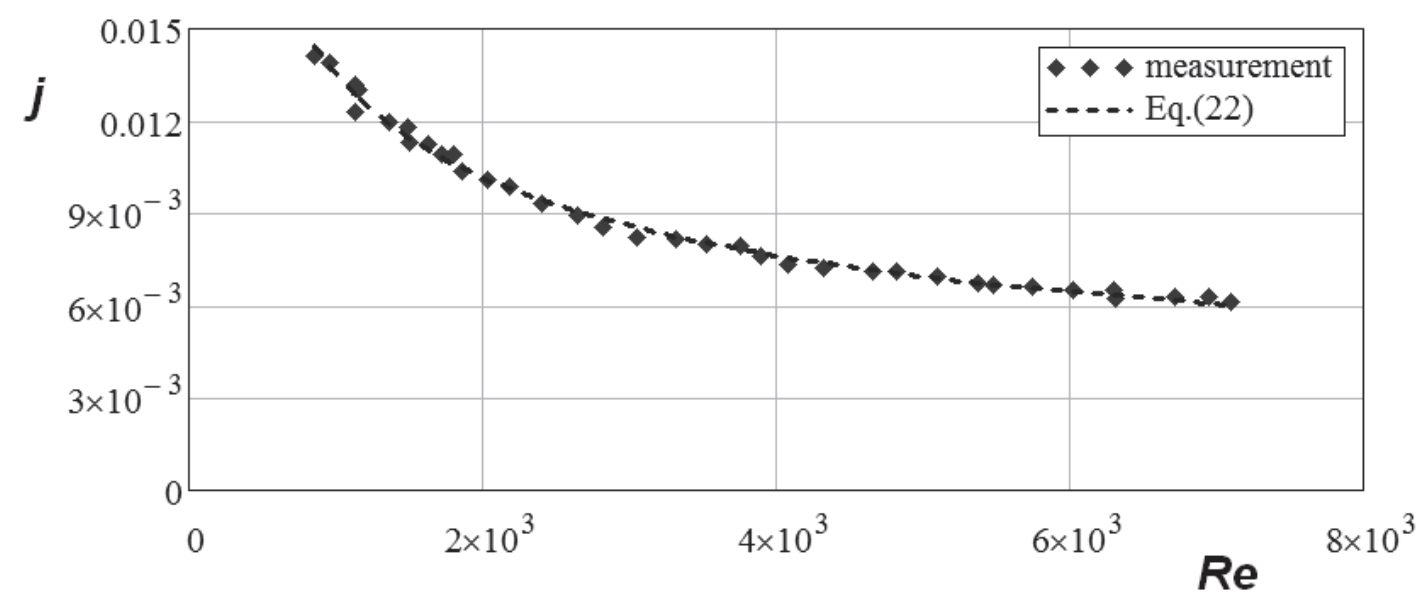

Fig. 14. The relationship of Colburn coefficient $j$ and Reynolds number for matrix composed of TE2 


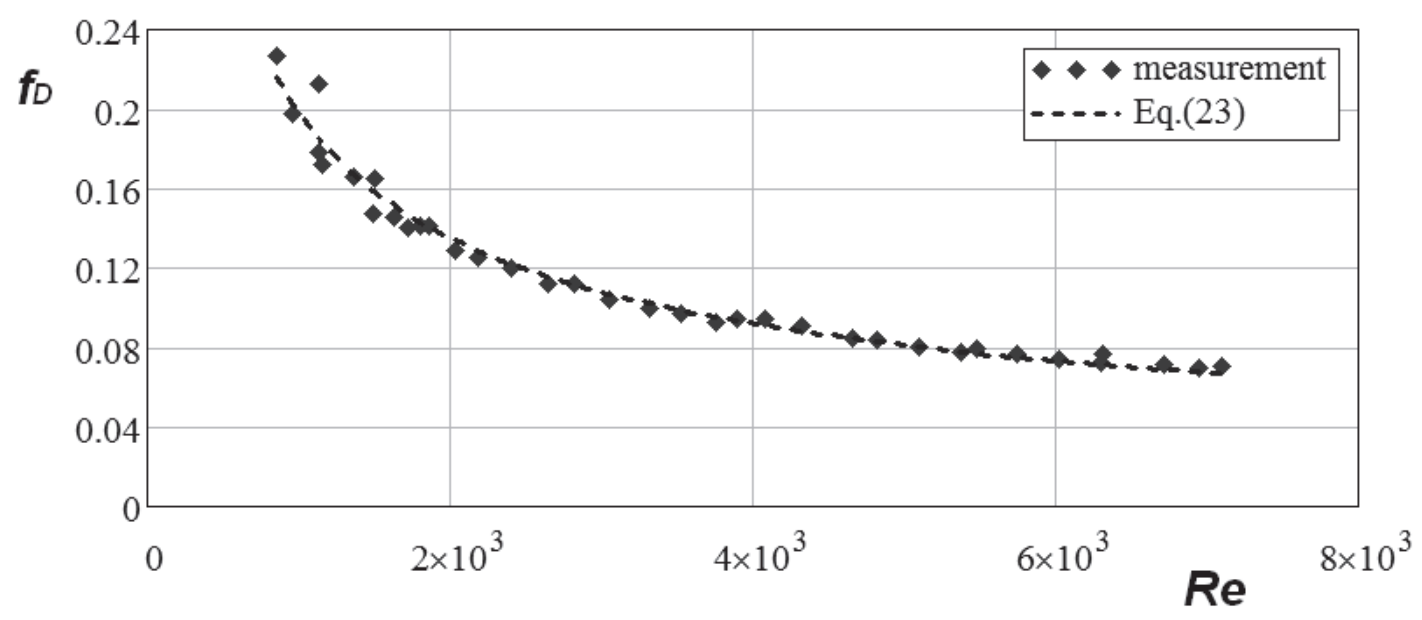

Fig. 15. The relationship between Darcy coefficient $f_{D}$ and Reynolds number for matrix composed of TE2

The uncertainty error of the values of Colburn coefficient $j$ and Darcy factor $f_{D}$ (Fanning coefficient $f$ ) was estimated with the sensitivity method and the mean error of $\pm 8 \%$ was obtained for the highest Reynolds numbers and $\pm 15 \%$ for the lowest Reynolds numbers.

\section{SUMMARY}

This paper presents a measurement methodology of the mean heat transfer and flow resistance coefficients for matrices composed of thermal elements of selected geometries that are applied in the rotational air preheaters. The indirect approach requires application of the appropriate model of heat transfer in the tested matrix. Therefore a selection of the appropriate heat transfer model was discussed along with appropriate methodology and measurement apparatus dedicated to the matrices of regenerative heat exchangers.

The current results involved a modification of this method proposed by Liang and Yang (1975). The measurement approach as well as the test apparatus described in detail in the paper were applied to determine mean heat transfer coefficients in new types of matrix geometry applied in regenerative air preheaters. Additionally, pressure drop was measured for these types of heat transfer elements. The dimensionless correlations for Colburn factor and Darcy factor as a function of the Reynolds number were proposed based on the obtained experimental data for the selected new geometries of the thermal elements. These correlations covered the laminar up to fully developed turbulent flow regimes. This is crucial especially for the so-called closed type of thermal profiles where due to their specific geometry separate gas flow ducts are formed, e.g. for the thermal matrix composed of TE1 thermal elements. In such a case the character of the dependence of heat transfer on flow rate will be different under laminar, transient and turbulent flow regime as demonstrated in the paper.

Very good agreement was demonstrated between the temperature profiles theoretically predicted on the basis of the selected heat transfer model and those measured. On the basis of the presented results it is fair to conclude that the proposed methodology proved to be useful and produced heat transfer data for the new types of regenerative air preheaters used as thermal elements.

The research results presented in the paper are supported by the Rafako S.A., Contract No. Z/ZK2/1600/12/KP. 


\section{SYMBOLS}

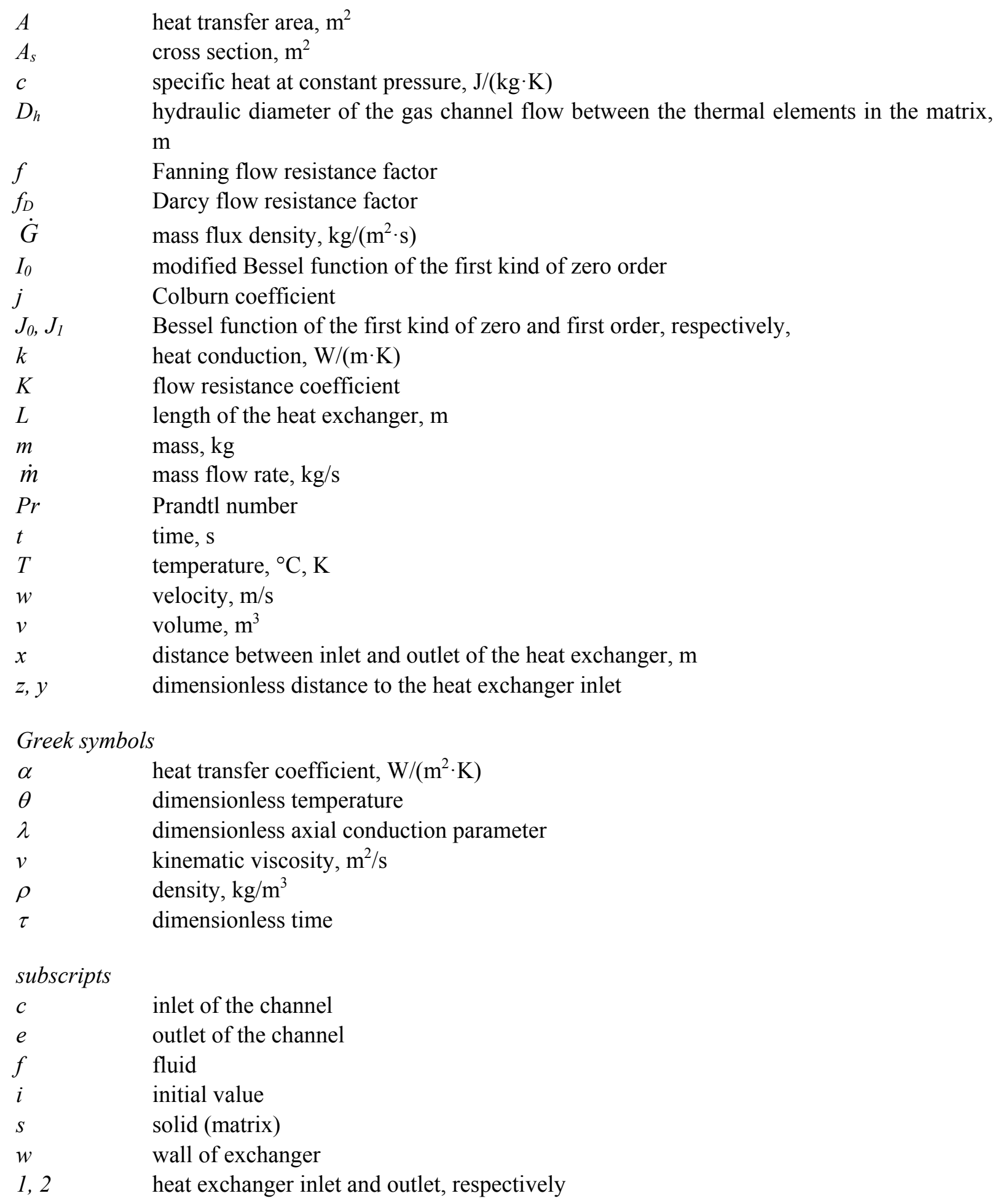

\section{REFERENCES}

Anzelius A., 1926. Über Erwärmung vermittels durchströmender Medien. Zeitschrift für Angewandte Mathematik und Mechanik, 6, 291-294.

Björck Å., Dahlquist G., 1987. Numerical methods. PWN, Warszawa (in Polish).

Butrymowicz D., Skiepko T., Karwacki J., Kwidziński R., Lackowski M., Przybyliński T., Gagan J., Śmierciew K., 2013. Analysis and experimental investigations of selected types of heating elements of rotational air 
preheaters OPP in terms of geometry and thermal and flow characteristics. Technical Report No. C2 - 11/2012, Gdansk (in Polish).

Cai Z.H., Li M.L., Wu Y.W., Ren H.S., 1984. A modified selected point matching technique for testing compact heat exchanger surfaces. Int. J. Heat Mass Transfer, 27, 971-978. DOI: 10.1016/0017-9310(84)90113-3.

Chang Z.-Ch., Hung M.-Sh., Ding P.-P., Chen P.-H., 1999. Experimental evaluation of thermal performance of Gifford-McMahon regenerator using an improved single-blow model with radial conduction. Int. J. Heat Mass Transfer, 42, 405-413. DOI: 10.1016/S0017-9310(98)00186-0.

Chen P.-H., Chang Z.-Ch., 1996. An improved model for the single-blow measurement including the nonadiabatic side wall effect. Int. Commun. Heat Mass Transfer, 23, 55-68. DOI: 10.1016/0735-1933(95)00084-4.

Chen P.-H., Chang Z.-Ch., 1997. Measurements of thermal performance of cryocooler regenerators using an improved single-blow method. Int. J. Heat Mass Transfer, 40, 2341-2349. DOI: 10.1016/S0017-9310(96)003006.

Crump K.S., 1976. Numerical inversion of Laplace transforms using a Fourier series approximation. J. Assoc. Comput. Mach., 23, 89-96. DOI: 10.1145/321921.321931.

Furnas C.C., 1932. Heat transfer from a gas stream to a bed of broken solids. US Bureau of Mines Bulletin, 361.

Howard C.P., 1964. The single blow problem including the effects of longitudinal conduction. ASME 1964 Gas Turbine Conference and Products Show, Houston TX, USA. Paper No. 64-GTP-11, pp. V001T01A011.

Kays W.M., London A.L., 1997. Compact heat exchangers. McGraw-Hill.

Larsen F.W., 1967.Rapid calculation of temperature in a regenerative heat exchanger having arbitrary initial solid and entering fluid temperatures. Int. J. Heat Mass Transfer, 10, 149-168. DOI: 10.1016/0017-9310(67)90095-6.

Leong K.C., Toh K.C., 1999. An experimental investigation of heat transfer and flow friction characteristics of louvered fin surfaces by the modified single blow technique. Heat Mass Transfer, 35, 53-63. DOI: $10.1007 / \mathrm{s} 002310050298$.

Liang C.Y., Yang. W.-J., 1975. Modified single-blow technique for performance evaluation on heat transfer surfaces. J. Heat Transfer, 97, 16-21. DOI: 10.1115/1.3450280.

Locke G.L., 1950. Heat transfer and flow friction characteristics of porous solids. Technical Report No. 10. Department of Mechanical Engineering, Stanford University, Stanford CA, USA.

Luo X., Roetzel W., Lüdersen U., 2001. The single-blow transient testing technique considering longitudinal core conduction and fluid dispersion. Int. J. Heat Mass Transfer, 44, 121-129. DOI: 10.1016/S0017-9310(00)000892 .

Schumann T.E.W., 1929. Heat transfer: A liquid flowing through porous prism. J. Franklin Inst., 208, $405-416$. DOI: 10.1016/S0016-0032(29)91186-8.

Pucci P.F., Howard C.P., Piersall C.H. Jr., 1967. The single-blow transient testing technique for compact heat exchanger surfaces. J. Eng. Power, 89, 29-38. DOI: 10.1115/1.3616604.

Stehfest H., 1970. Algorithm 368: Numerical inversion of Laplace transforms. Commun. ACM, 13, 47-49. DOI: $10.1145 / 361953.361969$.

Received 23 March 2016

Received in revised form 12 April 2016

Accepted 02 June 2016 